\title{
STUDI MODEL UNTUK PENINGKATAN PRESIPITASI AWAN KONVEKTIF DENGAN BUBUK GARAM
}

\author{
Belyaeva M.V', Drofa A.S $S^{1}$, Ivanov V. $N^{1}$ \\ Kudsy $M^{2}$, Haryanto $U^{2}$, Goenawan, R.D ${ }^{2}$, Harsanti, $D^{2}$ dan Ridwan ${ }^{2}$
}

\begin{abstract}
A study of use of polydisperse salt as seeding agent in cloud modification was conducted using 1-dimensional model. In this study the effects of introduction of the salt powder to cloud droplet distribution and the amount of precipitation enhancement were analyzed and compared to the results obtained by introduction of hygroscopic particles from pyrotechnic flares at various cloud media conditions such as cloud thickness, updraft, and original atmospheric condensation nuclei. This study reveals that polydisperse salt powder is usable to obtain precipitation from marginal cloud that usually can not produce precipitation.
\end{abstract}

\section{Intisari}

Sebuah studi tentang penggunaan garam serbuk polidispersi sebagai bahan semai telah dilaksanakan dengan memakai model 1-dimensi. Dalam studi ini pengaruh penambahan serbuk garam tersebut terhadap distribusi tetes awan dan jumlah penambahan presipitasi telah dilakukan, serta hasilnya telah dianalisa dan dibandingkan dengan hasil yang diperoleh pada pemakaian partikel higroskopis yang diperoleh dari flare piroteknik. Kondisi awan yang dipelajari terdiri dari beberapa macam ketinggian, updraft dan konsentrasi inti kondensasi atmosfer semula. Hasil studi menunjukkan bahwa bubuk garam polidisperse dapat dipakai untuk menghasilkan presipitasi dari awan marginal yang biasanya tidak mampu menghasilkan presipitasi.

Kata kunci : Model 1-dimensi, modifikasi awan, bubuk garam polidispersi

\section{PENDAHULUAN}

Partikel higroskopis dari flare piroteknik banyak digunakan dalam sejumlah proyek yang bertujuan untuk peningkatan curah hujan dari awan konvektif (Cooper et al., 1997). Pada modifikasi dengan metode ini partikel higroskopis dimasukkan pada daerah updraft di dasar awan. Konsep modifikasi adalah transformasi spektrum tetesan awan pada tahap awal kondensasi sedemikian rupa sehingga pada evolusi selanjutnya dari proses koagulasi awan akan menjadi lebih intens dan proses pembentukan curah hujan akan meningkat. Partikel higroskopis yang dihasilkan oleh senyawa piroteknik memiliki ukuran 0,3-1 $\mu \mathrm{m}$. Hasil investigasi menunjukkan bahwa penggunaan partikel yang lebih besar ( $-3 \mu \mathrm{m})$, memungkinkan untuk memperoleh efek modifikasi lebih signifikan, tetapi konsumsi agen (bahan semai) meningkat satu orde lebih besar peningkatan hasil yang diperoleh dari senyawa piroteknik.

\footnotetext{
${ }^{1}$ RPA "Typhoon", Rusia, email: drofa@typhoon.obninsk.ru

2 UPT Hujan Buatan, BPPT, Thamrin No. 8 Jakarta
}

Rosenfeld D. (2005, 2010) menyarankan penggunaan garam bubuk $\mathrm{NaCl}$ polydisperse dengan fungsi distribusi ukuran partikel yang agak luas untuk modifikasi awan. Bubuk garam tersebut telah diuji di Kamar Awan Besar SI RPA 'Typhoon' (Rusia) (Drofa et al., 2010). Hasil tes didukung oleh hasil simulasi numerik menunjukkan keunggulan yang signifikan dari bubuk untuk mendapatkan tambahan curah hujan. Efek penting dari modifikasi dengan bubuk garam tampak dengan sendirinya pada penambahan bubuk dengan konsentrasi massa yang 1-orde lebih sedikit dari pada penggunaan flare piroteknik. Ketika digunakan bubuk garam, curah hujan dapat diperoleh dari awan konvektif hangat yang kecil biasanya tidak menghasilkan presipitasi (non-precipitating convective cloud).

Makalah ini memberikan gambaran (berdasarkan simulasi numerik) perkiraan efek modifikasi pada awan konvektif yang disebabkan oleh bubuk garam polydisperse dan menggambarkan kondisi yang diperlukan untuk efek positif maksimum yang dapat dicapai dengan metode ini. 


\section{METODOLOGI}

Analisis skenario pembentukan tetes awan pada awan konvektif menunjukkan bahwa pada tahap awal kondensasi tetesan awan utama ukuran spektrum distribusi dibentuk pada inti higroskopis dengan jari-jari 0,015-0,65 $\mu \mathrm{m}$. Spektrum awan maksimum terbentuk pada inti (nuclei) dengan radius sekitar $0,02 \mu \mathrm{m}$. Hanya partikel higroskopis tersebut yang merupakan inti kondensasi aktif yang pertumbuhannya "tak terbatas" pada tahap kondensasi awal direalisasikan. Untuk stimulasi secara artifisial dari proses koagulasi dalam awan tersebut diperlukan perubahan spektrum tetesan pada tahap awal kondensasi sedemikian rupa sehingga jumlah tetes besar akan meningkat tanpa terjadi perubahan kondisi pembentukan tetes awan pada inti kondensasi atmosfer (inti kondensasi yang semula ada). Untuk partikel higroskopis dengan jari-jari lebih besar 0,5-0,6 $\mu \mathrm{m}$ harus ditambahkan dari luar. Jumlah partikel tambahan yang diperlukan untuk intensifikasi peristiwa koagulasi, dan pembentukan curah hujan berikutnya ditentukan dapat ditentukan dari hasil simulasi numerik.

Distribusi ukuran partikel higroskopis pada simulasi numerik digambarkan oleh fungsi dalam bentuk:

$$
f(r)=r^{-\mu} \exp \left(-\left(r / r_{0}\right)^{2}\right.
$$

Spektrum partikel bubuk garam mengikuti persamaan (1). Untuk bubuk yang disajikan dalam (. Drofa et al, 2010) parameter distribusi (1) sama dengan: $\mu=1,5, r_{0}=5 \mu \mathrm{m}$, dan untuk bubuk dalam (. Drofa et al, 2011) $-\mu=0,5, r_{0}=5,3 \mu \mathrm{m}$. Contoh perhitungan dari tahap awal formasi struktur mikro medium awan dengan penambahan bubuk garam ke lapisan sub-cloud ditunjukkan pada Gambar. 1. Berikut ditampilkan hasil perhitungan dari spektrum tetes awan pada paras yang dapat tercapai oleh udara dalam waktu 120s. Karakteristik kimia dan fisika dari aerosol latar mewakili karakteristik ratarata aerosol atmosfer benua, demikian pula kondisi atmosfer adalah tipikal untuk awan konvektif daerah benua. Kecepatan updraft didekat dasar awan $\mathrm{V}=$ $1,5 \mathrm{~m} / \mathrm{s}$, suhu atmosfer semula $10^{\circ} \mathrm{C}$, tekanan 900 $\mathrm{mb}$. Distribusi partikel aerosol awal yang bersifat inti kondensasi didekati dengan persamaan Junge:

$$
f\left(r_{c}\right)=a \cdot r^{-v}
$$

Formula (2) mendekati cukup baik spektrum sebenarnya partikel aerosol di atmosfer. Untuk massa udara benua itu biasanya dianggap $v=4-5$ (Drofa, 2006).

Jadi jelaslah bahwa efek positif dari modifikasi awan dengan bubuk garam mungkin hanya muncul ketika sejumlah relatif partikel tambahan diperkenalkan kurang dari $0,5 \mu \mathrm{M}$ tidak melebihi jumlah inti kondensasi aktif dalam aerosol latar. Ini berarti bahwa kondisi $\mu<v$ harus dipenuhi. Dalam kasus sebaliknya $(\mu>v)$ penambahan partikel akan menyebabkan peningkatan konsentrasi partikel yang terbentuk dan penurunan ukuran rata-rata nya. Efek ini disebut "overseeding".

Sebagai contoh pada Gambar 1 ditampilkan adalah ukuran spektrum tetes awan pada penambahan partikel higroskopis ke lapisan konvektif sub-cloud (dasar awan) dengan fungsi distribusi ukuran yang sempit. Partikel $\mathrm{NaCl}$ dengan radius yang efektif dari $1 \mu \mathrm{m}$ dan dispersi relatif dari fungsi distribusi ukuran $S=0,3$ digunakan. Konsentrasi jumlah partikel diperkenalkan membuat $120 \mathrm{~cm}^{3}$.

Seperti konsentrasi optimal untuk partikel ukuran ini untuk mendapatkan efek maksimum modifikasi (Drofa, 2006). Konsentrasi massa

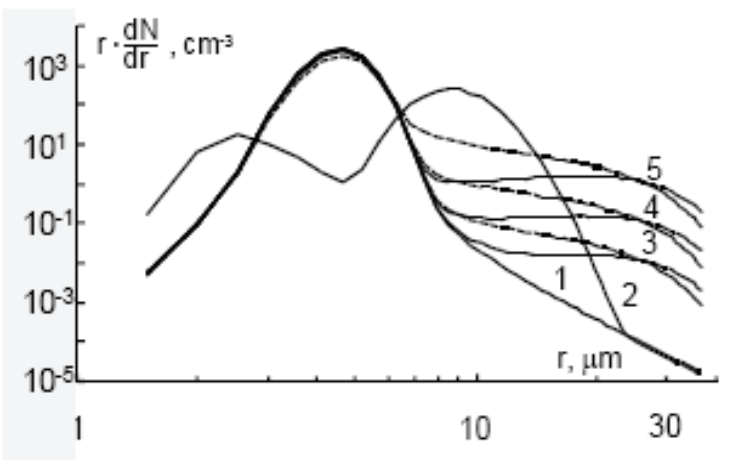

Gambar 1. Spetrum tetes awan 2 menit setelah terjadinya pembentukan awan.

Garis solid - bubuk garam dari RPA Typhoon.

Garis putus - bubuk garam pada (Drofa, 2010)

1 - spektrum tetes pada konsentrasi latar

2 - spektrum tetes pada penambahan partikel garam dengan radius $1 \mu$

3 - spektrum tetes pada penambahan garam dengan konsentrasi massa $0.01 \mathrm{mg} / \mathrm{m}^{3} ; 4-0.1 \mathrm{mg} / \mathrm{m}^{3} ; 5$ $1 \mathrm{mg} / \mathrm{m}^{3}$

partikel adalah $1,1 \mathrm{mg} / \mathrm{m}^{3}$. Seperti terlihat dari Gambar 1, penambahan partikel tersebut berakibat pembentukan spektrum tetes awan bimodal yaitu fraksi besar tetes yang ditentukan oleh pertumbuhan partikel yang terbentuk pada partikel garam, dan fraksi halus tetesan awan - diatas inti dari aerosol latar. Studi-studi tentang efek modifikasi dengan partikel tersebut telah menunjukkan (Drofa, 2006;. Segal et al, 2007) bahwa pada penambahan partikel garam akibat penurunan kejenuhan berlebih (oversaturation) dari uap air di awan, maka jumlah inti atmosfer diaktifkan (yaitu mereka berubah menjadi tetes awan) pada tingkat yang lebih rendah daripada di awan latar. Karena hal ini, konsentrasi total tetes awan yang terbentuk pada latar dan inti tambahan tampak kurang dibandingkan kasus ketika inti kondensasi tambahan tidak hadir. Ukuran rata-rata awan tetes muncul lebih besar 
pada penambahan partikel. Karena efek positif modifikasi dengan partikel higroskopis dengan distribusi ukuran yang sempit terjadi sebagai akibat pembesaran tetes awan adalah faktor utama yang memicu terjadinya koagulasi yang diinduksi oleh gravitasi dalam awan dan memicu pembentukan curah hujan berikutnya. Satu hal yang harus diperhatikan adalah fakta bahwa ukuran tetes awan yang terbentuk pada modifikasi mempunyai ukuran lebih kecil dibandingkan tetes yang terjadi pada awan latar. Ini berarti bahwa dalam kasus ini modifikasi dengan partikel garam menghasilkan perubahan kondisi pembentukan tetes awan pada inti kondensasi atmosfer.

Modifikasi awan dengan bubuk garam tidak menyebabkan perubahan seperti yang disebutkan pada paragraf diatas bahkan dengan penambahkan garam dengan konsentrasi massa yang cukup besar. Jumlah tetes awan yang terjadi dari partikel aerosol latar sedikit dalam kasus ini. Sebagaimana dapat dilihat pada Gambar 1, penambahan bubuk garam ke dalam level sub-cloud pada awan konvektif mengakibatkan terjadinya "ekor" (tail) untuk butir besar pada kurva distribusi tetes awan. Spektrum tetes yang terjadi pada partikel atmosfer latar dalam hal ini tidak mengalami perubahan. Sebagaimana ditunjukkan dari analisis hasil pemodelan numeris, modifikasi dengan bubuk garam secara signifikan menghasilkan terjadinya koagulasi yang lebih intensif (yang kemudian mengakibatkan proses penambahan presipitasi) dibandingkan dengan partikel higroskopis dengan distribusi yang sempit.

Data yang diperoleh pada tahap awal kondensasi (Gambar 1) adalah data dasar untuk menghitung perubahan (evolusi) struktur mikro medium awan dengan model numeris 1-dimensi (Drofa, 2010). Model 1 dimensi tersebut menggambarkan evolusi medium awan pada bagian tengah awan sebagai variabel dari kecepatan vertikal dari udara naik yang membentuk awan tersebut. Model ini secara parametris memperhitungkan panas dan uap air karena masuk dari lingkungan karena entrainment. Aktifasi inti kondensasi atmosfer terjadi pada lapisan subcloud (lapisan dibawah awan). Dengan adanya massa udara yang naik selanjutnya, perubahan mikrostruktur medium awan terjadi karena adanya kondensasi, pertambahan/penguapan tetes, koagulasi, pemecahan dan sedimentasi butir2 awan. Struktur spatiotemporal parameter2 meteorologis dan karakteristik integral dari fungsi distribusi ukuran butir dihitung dengan model ini. Kandungan air liquid (LWC) dari tetes-tetes besar dengan ukuran $r>200 \mu \mathrm{m}$ yang mencirikan presipitasi dihitung pula berdasarkan model. Jumlah dan intensitas presipitasi dihitung berdasarkan data yang merepresentasikan dasar awan.

\section{HASIL DAN PEMBAHASAN}

Tren temporal dari intensitas presipitasi dihitung pada modifikasi awan yang tebalnya 4,2 km dengan bubuk garam ditunjukkan pada Gambar 2.

Pada tahap awal pembentukan awan ini, kadar air cair maksimum 3,46 g/m $\mathrm{m}^{3}$ dan kecepatan udara vertikal updraft maksimum 4,5 m / s. Penambahan partikel ke dalam lapisan sub-awan dengan ketebalan 60-240 m dilakukan pada menit ke-10 dari awal pembentukan awan. Dari grafik pada Gambar 2 terlihat bahwa dengan penambahan bubuk garam, jumlah presipitasi dapat mencapai 2-5 kali lebih besar. Pengaruh modifikasi disebabkan oleh penggunaan bubuk yang diproduksi di RPA 'Typhoon', seperti yang terlihat dari Gambar 2, agak lebih menonjol daripada yang

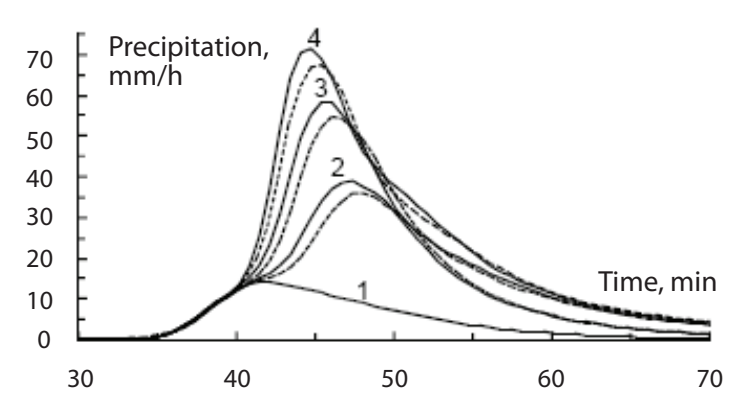

Gambar 2. Intensitas Temporal tren curah hujan dari awan tebal 4,2 km. Garis padat - bubuk garam RPA 'Typhoon'; garis putus-putus bubuk disajikan dalam (Drofa et al, 2010.).

1 - tanpa agen,

2 - konsumsi bahan garam, 2,4 kg/ $\mathrm{km}^{2}$

$3-12 \mathrm{~kg} / \mathrm{km}^{2}$,

$4-48 \mathrm{~kg} / \mathrm{km}^{2}$.

telah disajikan sebelumnya (Drofa et al., 2010). Secara umum, hasil perhitungan menunjukkan bahwa tambahan curah hujan yang diperoleh dari modifikasi modifikasi awan dengan bubuk dari RPA 'Typhoon' adalah dengan 1-2 mm lebih dari pada modifikasi dengan bubuk disajikan dalam (Drofa et al., 2010). Untuk mendapatkan jumlah tambahan presipitasi yang sama dibutuhkan jumlah bubuk garam $10-15 \%$ lebih sedikit dari yang pertama.

Jumlah presipitasi terhitung karena modifikasi dapat dilihat pada Gambar 3. Sebagaimana terlihat pada Gambar tersebut, tambahan curah hujan terjadi terjadi dengan adanya penambahan bubuk garam $>2,4 \mathrm{~kg} / \mathrm{km}^{2}$ pada awan dengan ketebalan $2,5-3,5 \mathrm{~km}$. Awan ini biasanya tidak memberikan presipitasi secara alami (tanpa penambahan garam). Efek penyemaian yang maksimal - atau penambahan presipitasi maksimal - terjadi pada penambahan bubuk garam sebanyak $4,8 \mathrm{~kg} / \mathrm{km}^{2}$. 
Dengan penambahan terakhir ini, semua tetes awan berubah menjadi tetesan presipitasi. Setelah terjadinya presipitasi dari awan tersebut sejumlah tetes awan masih tertinggal di dalam awan, namun dengan penambahan bubuk garam lebih lanjut tidak menghasilkan presipitasi tambahan.

Hasil perhitungan dari efek modifikasi yang dicapai dengan menggunakan flare piroteknik Afrika Selatan (Cooper et al., 1997) menunjukkan bahwa sejumlah besar tambahan curah hujan hanya terjadi pada modifikasi awan dengan ketebalan lebih dari $4 \mathrm{~km}$. Perhitungan dibuat untuk konsumsi $12 \mathrm{~kg}$ agen per $1 \mathrm{~km}^{2}$ awan yang disemai. Penggunaan partikel dalam jumlah yang lebih sedikit tidak memberikan pengaruh modifikasi yang signifikan Hasil yang disajikan di sini adalah sesuai dengan data percobaan lapangan pada penyemaian dengan partikel tersebut (Mather et al., 1997). Seperti terlihat dari Gambar 3, penyemaian dengan garam bubuk hasil dalam peningkatan curah hujan yang signifikan. Pada konsumsi bubuk

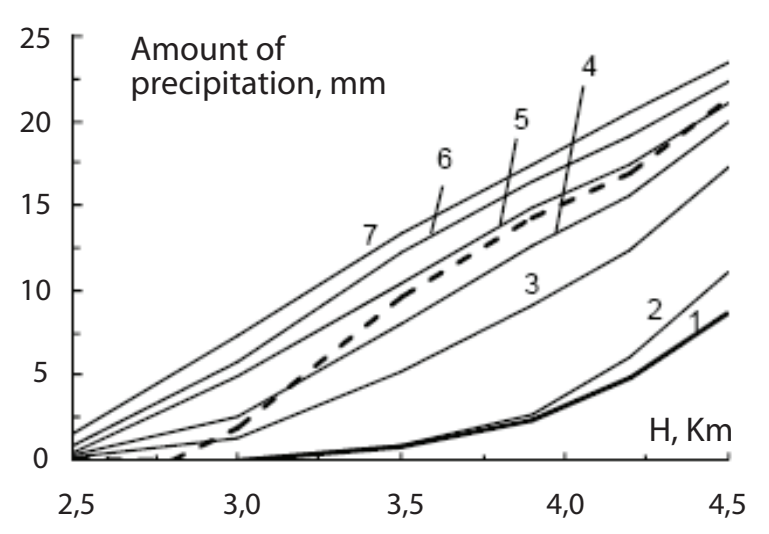

Gambar 3. Perhitungan hasil jumlah total presipitasi dari awan dengan ketebalan yang berbeda. 1 - tanpa penambahan partikel, 2 penambahan partikel flare Afrika Selatan, 3 - Masuknya bubuk garam pada konsumsi $2,4 \mathrm{~kg} / \mathrm{km}^{2}, 4-6 \mathrm{~kg} / \mathrm{km}^{2}, \quad 5-12 \mathrm{~kg} / \mathrm{km}^{2}$, $6-24 \mathrm{~kg} / \mathrm{km}^{2}, 7-48 \mathrm{~kg} / \mathrm{km}^{2}$. Garis putus putus - penambahan partikel garam ukuran $1 \mu \mathrm{M}$ dg konsumsi $64 \mathrm{~kg} / \mathrm{km}^{2}$.

garam 2,4 kg/km² jumlah curah hujan yang jatuh dari awan dengan ketebalan kurang dari $4 \mathrm{~km}$ lebih besar dari pada penyemaian dengan partikel piroteknik di konsumsi 12 kg/km².

Pengaruh penyemaian dengan partikel bubuk garam polydisperse secara signifikan juga lebih besar dari hasil penyemaian dengan partikel garam besar dengan distribusi ukuran partikel yang sempit. Dari Gambar 3 terlihat bahwa efek penyemaian dengan partikel garam (radius efektif $1 \mu \mathrm{m}$ dan konsentrasi berat optimum $1,1 \mathrm{mg} / \mathrm{m}^{2}$ ) pada konsumsi garam total $64 \mathrm{~kg} / \mathrm{km}^{2}$ tampaknya memberikan hasil kurang dari pada dengan penyemaian bubuk garam pada konsumsi $12 \mathrm{~g} /$ $\mathrm{km}$ yang kedua.

Dari hasil simulasi numerik tampak bahwa efek dari penyemaian dengan bubuk garam tergantung secara signifikan pada kondisi atmosfer di mana awan konvektif terbentuk. Gambar 4 menyajikan hasil perhitungan untuk intensitas presipitasi pada penyemaian dengan bubuk garam pada awan dengan ketebalan $3 \mathrm{~km}$. Awan tersebut secara alami tidak akan menghasilkan presipitasi. Maksimum kadar air cair (LWC) media awan di awan yang dimodelkan mencapai $2,56 \mathrm{~g} / \mathrm{m}^{3}$. Perlu disebutkan disini bahwa pada penyemaian awan dengan ketebalan tersebut dan dengan kadar air cair kurang dari $2 \mathrm{~g} / \mathrm{m}^{3}$ praktis tidak memberikan hasil curah hujan bahkan pada konsumsi bubuk garam yang sangat besar. Seperti terlihat dari Gambar 4, efek penyemaian dengan bubuk garam paling menonjol di awan dengan konsentrasi tetes awan yang besar dan kecepatan updraft yang lebih rendah.

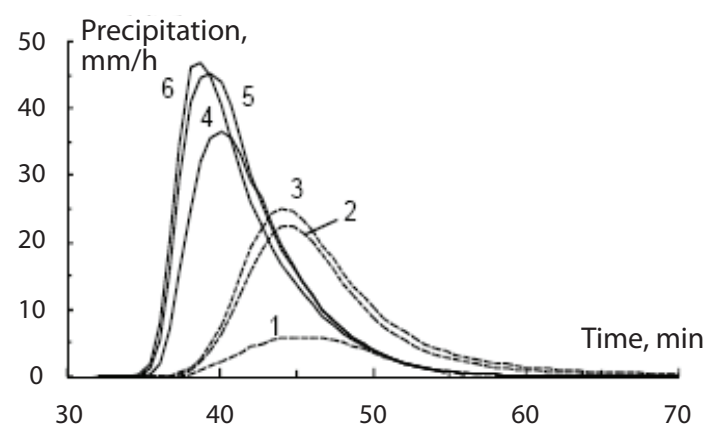

Gambar 4. Trend Intensitas Temporal curah hujan dari awan dengan ketebalan $3 \mathrm{~km}$ di modifikasi dengan bubuk garam di konsumsi dari 48 $\mathrm{kg} / \mathrm{km}^{2}$. Garis tebal - updraft udara maksimum $\mathrm{Vm}=3,3 \mathrm{~m} / \mathrm{s}$, garis putus-putus - $\mathrm{Vm}=5 \mathrm{~m} / \mathrm{s}$. 1,4 - konsentrasi tetes $\mathrm{N}$ $=1015 \mathrm{~cm}^{3}, 2,5-\mathrm{N}=485 \mathrm{~cm}^{3}, 3,6-\mathrm{N}$ $=305 \mathrm{~cm}^{3}$.

Hasil simulasi numerik di atas konsisten dengan pengamatan di lapangan. UPT Hujan Buatan, Indonesia melaksanakan kegiatan operasional penyemaian awan di DAS Larona (Sulawesi) dan Kawasan DAS Citarum (Jawa). Hasil yang dicapai menunjukkan bahwa selama penyemaian awan dengan kondisi atmosfer yang menguntungkan di Larona Catchment area pada April 2005 mengakibatkan 3 kali lebih besar dari total curah hujan dibanding dengan hasil di DAS Citarum yang dilakukan di bawah kondisi yang tidak menguntungkan pada bulan Februari 2011 karena badai konvektif yang terbentuk (Haryanto dkk, 2011). Salah satu beda signifikan dari kondisi atmosfer dari dua daerah tersebut adalah suhu dasar awan atmosfer Suhu (Tccl) - berasal dari 
analisis sounding atmosfer - yang berperan penting dalam aktivitas koalesensi dalam awan konvektif.

\section{KESIMPULAN}

Hasil dari studi yang telah dilakukan menunjukkan bahwa penggunaan garam bubuk polydisperse untuk mendapatkan sejumlah tambahan curah hujan dari awan konvektif hangat lebih menguntungkan terhadap penggunaan partikel higroskopis yang dihasilkan oleh flare piroteknik relatif terhadap agen konsumsi dan efek modifikasi. Pada penyemaian dengan bubuk garam tambahan curah hujan dapat diperoleh dari awan konvektif hangat dengan ketebalan moderat yang tidak memberikan curah hujan di bawah kondisi biasa. Dalam hal ini pula efek "overseeding", yang dapat membuyarkan awan seperti yang terjadi pada modifikasi dengan fine partikel dari flare piroteknik tidak terjadi pada modifikasi dengan penggunaan bubuk garam.

\section{DAFTAR PUSTAKA}

Cooper W.A., Bruintjes R.T., Mather G.K., Calculations pertaining to hygroscopic seeding with flares. J. Appl. Meteorol., 36, 1449-1469, 1997.

Drofa A.S., Formation of cloud microstructure: the role of hygroscopic particles. Atmos. Ocean. Phys., 42, 326-336., 2006.

Drofa A.S., Studies of a Modification Effect from a Warm Convective Cloud Seeding by Hygroscopic Particles Based on Numerical Simulation Results. Atmos. Ocean. Phys., 46, 346-359, 2010.
Drofa A.S., Ivanov V.N., Rosenfeld D., Shilin A.G., Studying an Effect of Salt Powder Seeding Used for Precipitation Enhancement from Convective Clouds. Atmos. Chem. Phys., 10, 8011-8023, 2010.

Drofa A.S., Eran'kov V.G., Ivanov V.N., Shilin A.G., Yaskevich G.F., Experimental studies of salt powder efficiency at convective cloud modification for precipitation enhancement, 2011 [in present proceedings].

Haryanto, U., D. Harsanti, R.D. Goenawan, K. Adithya, Analysis of Storm Category and Coalescence Activity: Relationship to The Daily Mean Catchment Rainfall (Cases Cloud Seeding Operational in Larona and Citarum Catchment Area). Paper submitted to Tenth WMO Scientific Conference on Weather Modification, Bali October 2011.

Mather G.K., Terblanche D.E., Steffens F.E., Fletcher L., Results of South African cloudseeding experiments using hygroscopic flares, J. Appl. Met., 36, 1433-1447, 1997.

Rosenfeld D., Lahav R., The Search for the Optimal Size of Hygroscopic Seeding Particles. Proceedings of the 16-th Conference on Planned and Inadvertent Weather Modification, San Diego, USA, 2005.

Rosenfeld D., Axisa D., Woodley W.L. and Lahav R., A Quest for Effective Hygroscopic Cloud Seeding. J. Appl. Met. Climate, 49, 1548-1562, 2010.

Segal Y, Pinsky M. and Khain A., The Role of Competition Effect in the Raindrop Formation. Atmos. Res., 83, 106-118, 2007. 
